\title{
Correction to: Droplet-vitrification cryotherapy and thermotherapy as efficient tools for the eradication of apple chlorotic leaf spot virus and apple stem grooving virus from virus-infected quince in vitro cultures
}

\author{
Sakineh Farhadi-Tooli • Alireza Ghanbari • Maryam Jafarkhani Kermani • \\ Mehrshad Zeinalabedini · Jean Carlos Bettoni · Amir Mohammad Naji • \\ Nooshin Kazemi
}

Published online: 28 October 2021

(C) Koninklijke Nederlandse Planteziektenkundige Vereniging 2021

\section{Correction to: Eur J Plant Pathol}

https://doi.org/10.1007/s10658-021-02400-X

This erratum is published as author noticed formatting errors with Table 2.

Original article has been updated.

The original article can be found online at https://doi.org/ 10.1007/s10658-021-02400-x.

S. Farhadi-Tooli $\cdot$ A. Ghanbari $(\bowtie)$

Department of Horticulture Sciences, Faculty of Agriculture and Natural Resources, University of Mohaghegh Ardabili, P. O. Box: 179, Ardabil, Iran e-mail: ghanbari66@uma.ac.ir

\section{J. Kermani ( $\bowtie)$}

Department of Tissue and Cell Culture, Agricultural Research, Education and Extension Organization (AREEO), Agricultural Biotechnology Research Institute of Iran (ABRII), 31359-33151 Karaj, Iran e-mail:m.j.kermani@abrii.ac.ir; Maryam.j.kermani@ gmail.com

\section{Zeinalabedini}

Department of Systems and Synthetic Biology, Agricultural Biotechnology Research Institute of Iran (ABRII), Agricultural Research Education and Extension Organization (AREEO), 31359-33151 Karaj, Iran
J. C. Bettoni

The New Zealand Institute for Plant and Food Research Limited, Private Bag 11600, Palmerston North 4442, New Zealand

A. M. Naji

Department of Agronomy and Plant Breeding, Faculty of Agriculture, Shahed University, Tehran, Iran

N. Kazemi

Temperate Fruits Research Center, Agricultural Research, Education and Extension Organization (AREEO),

Horticultural Sciences Research Institute, Karaj, Iran 